\title{
Mercados de trabajo y sistemas de pensiones
}

\section{Andras Uthoff \\ Unidad de Estudios \\ Especiales, CEPAL \\ authoff@eclac.cl}

América Latina experimenta un proceso simultáneo de envejecimiento de la población y de precarización del empleo que desafía a los sistemas de pensiones contributivos. Los pilares de reparto ven afectada su solvencia por seculares descensos en el número de personas activas que contribuyen a financiar los beneficios de las personas retiradas. Los beneficios de los pilares de capitalización individual son sensibles a la densidad de cotización necesaria para acumular capitales y financiar pensiones por un período cada vez más largo de sobrevivencia del afiliado. El presente trabajo ilustra la forma en que este desafío se manifiesta en la actualidad, y explora las responsabilidades que tendrá la sociedad en su superación. 


\section{I}

\section{Introducción}

Los sistemas de pensiones diseñan mecanismos destinados a asegurar el financiamiento del consumo durante la vejez o invalidez de un trabajador, y el de sus dependientes en caso de que éste muera. El propósito de tales sistemas es resolver el problema económico de destinar parte de la producción a esas contingencias (Barr, 2000), para lo cual necesitan identificar las fuentes de financiamiento con que han de solventarse los costos de esa producción. Puede ser el ahorro de los trabajadores y de sus empleadores; pueden ser los impuestos para el financiamiento público de las prestaciones, y pueden ser las primas de seguros para solventar los costos en casos de invalidez y muerte. Si los sistemas no incluyen todos estos esquemas de financiamiento y de seguros, es muy probable que dejen a muchas personas sin protección alguna.

Este trabajo explica por qué las actuales reformas que se apoyan en esquemas de ahorro y seguros privados individuales (Mesa-Lago, 1999), reproducen la desigualdad de la sociedad y tienden a desvirtuar los propósitos de la seguridad social, de la cual son parte los sistemas de pensiones. En efecto, al obtener el financiamiento a partir de la relación contractual del afiliado, los sistemas de ahorro para el retiro reproducen los problemas propios de los mercados de trabajo de la región. Como gran parte de las personas en edad de trabajar se encuentran desempleados, subempleados e inactivos, un sistema que basa en estos esquemas la protección para consumir durante la vejez o invalidez del

\section{II}

\section{El contexto}

El mercado de trabajo limita la cobertura poblacional de los sistemas de pensiones en América Latina. Podemos distinguir tres fenómenos del contexto que contribuyen a ello.

\footnotetext{
$\square$ Este trabajo fue preparado con ocasión del Taller sobre Economía y Envejecimiento Demográfico (México, D.F., 16 y 17 de mayo de 2002), organizado por el Centro Interamericano de Estudios de Seguridad Social (CIESS), El Colegio de la Frontera Norte (COLEF) y
}

perceptor principal de ingresos o tras su muerte, dejará a muchas personas subaseguradas o no aseguradas.

Los sistemas de pensiones en América Latina evolucionarán conforme a la voluntad política y a las acciones institucionales que se realicen para resolver este dilema. La evolución dependerá del grado de solidaridad del sistema, y del tipo de subsidios cruzados que se diseñen desde quienes tienen mayor capacidad de ahorro hacia los que tienen menor capacidad. La sociedad necesita definir el papel redistributivo del sistema y la forma como éste se implementará: si se hará dentro del sistema (mediante cotizaciones solidarias) o desde fuera del sistema (mediante impuestos generales), evitando el riesgo moral de que quienes puedan ahorrar se acojan a los subsidios.

Para resaltar la importancia de este vínculo con las desigualdades asociadas a los mercados de trabajo, este ensayo examina a continuación el contexto demográfico, económico y laboral en el que operan los sistemas (sección II); las funciones que los sistemas deben cumplir en esos contextos (sección III); las opciones básicas para diseñar los pilares de los sistemas (sección IV); los pilares extremos que se pueden construir (sección V); la heterogeneidad en el acceso a las prestaciones de los pilares de ahorro individual (sección VI); los pasivos contingentes asociados a las diferentes opciones (sección VII); los resultados que estamos observando en sistemas con pilares de ahorro individual (sección VIII), y las conclusiones (sección IX).

En primer lugar, las características del acelerado envejecimiento de la población contienen elementos positivos y negativos. Por el lado positivo, sigue au-

la Universidad Nacional Autónoma de México (UNAM). El autor agradece los comentarios recibidos de la Dra. Patricia Olave durante el taller y los de Oscar Altimir a un primer borrador, y el apoyo de Nora Ruedi en la preparación de esta versión. El autor es el único responsable por su contenido. 
mentando la población en edad de trabajar y que participa en la actividad económica (la potencialmente activa y con capacidad de ahorro). También es positivo el hecho de que desciende el número total de personas dependientes de ella (jóvenes en edad escolar, adultos que no trabajan y ancianos no activos). Sin embargo, aumentan cada vez más aquéllas en edad de jubilar (véase la columna más a la derecha del gráfico 1). Este indicador cuantitativo de envejecimiento de la población está elevándose con rapidez y comenzará a hacerlo con más fuerza a partir del año 2020.

En segundo lugar, las economías están operando con niveles de ahorro e inversión en torno al $20 \%$ del PIB, los que resultan muy bajos para las necesidades de la región. Según estudios de la CEPAL, con esos niveles no es posible crecer a los ritmos necesarios para mantener plenamente ocupados a todos los económicamente activos (CEPAL, 1996). Aun más, se aprecia que cuando las economías son capaces de atraer financiamiento del exterior en forma de ahorro externo (aumento del financiamiento con capitales externos), éste no complementa el ahorro nacional, sino que disminuye el ahorro que hacen los nacionales. De esta manera ambas fuentes de financiamiento tienden a sustituirse entre sí (Titelman y Uthoff, 1997, y gráfico 2).

En tercer lugar, y como lo destacan los análisis de la CEPAL, el crecimiento económico ha estado dependiendo principalmente del financiamiento externo, cuyas fuentes han sido altamente volátiles. Sumada al carácter procíclico de las políticas macroeconómicas de la región, esta situación se ha reflejado en crisis financieras inusitadamente frecuentes y en un crecimiento económico bajo e inestable, con costos importantes en términos de desempleo y de incidencia de la pobreza (Ocampo, coord., 2001). De hecho, como ya lo han venido señalando la Organización Internacional del Trabajo (оIт) y la CEPAL, los ocupados soportan una creciente precariedad que se manifiesta en mayores

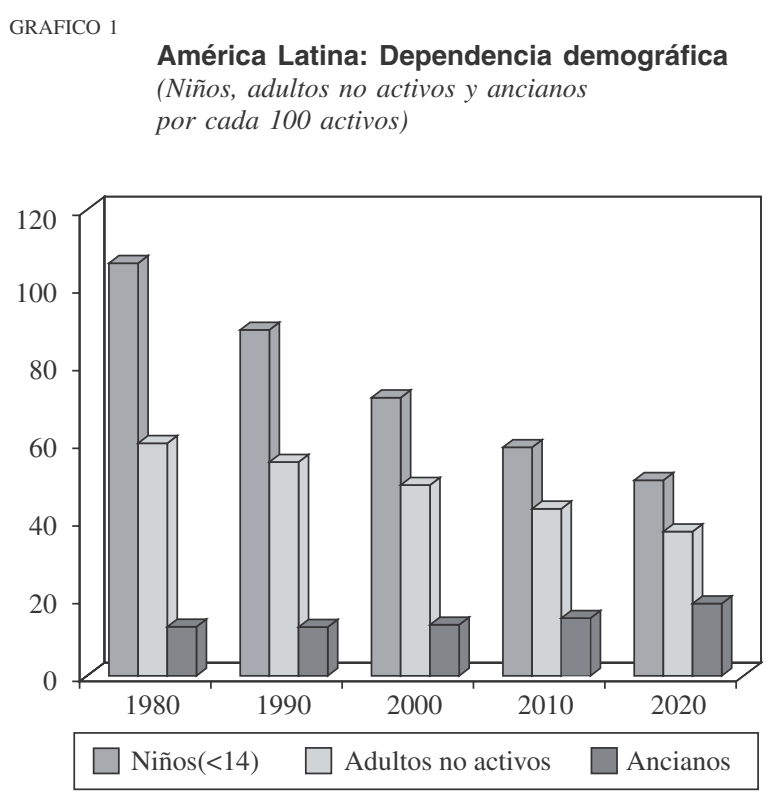

Fuente: CEPAL/CELADE, 1999 y 2002.

GRAFICO 2

América Latina y el Caribe: Ahorro nacional bruto, ahorro externo e inversión real (En porcentaje del PIB, sobre la base de dólares corrientes - ahorro nacional bruto y ahorro externo-y dólares constantes de 1995 para la inversión real)

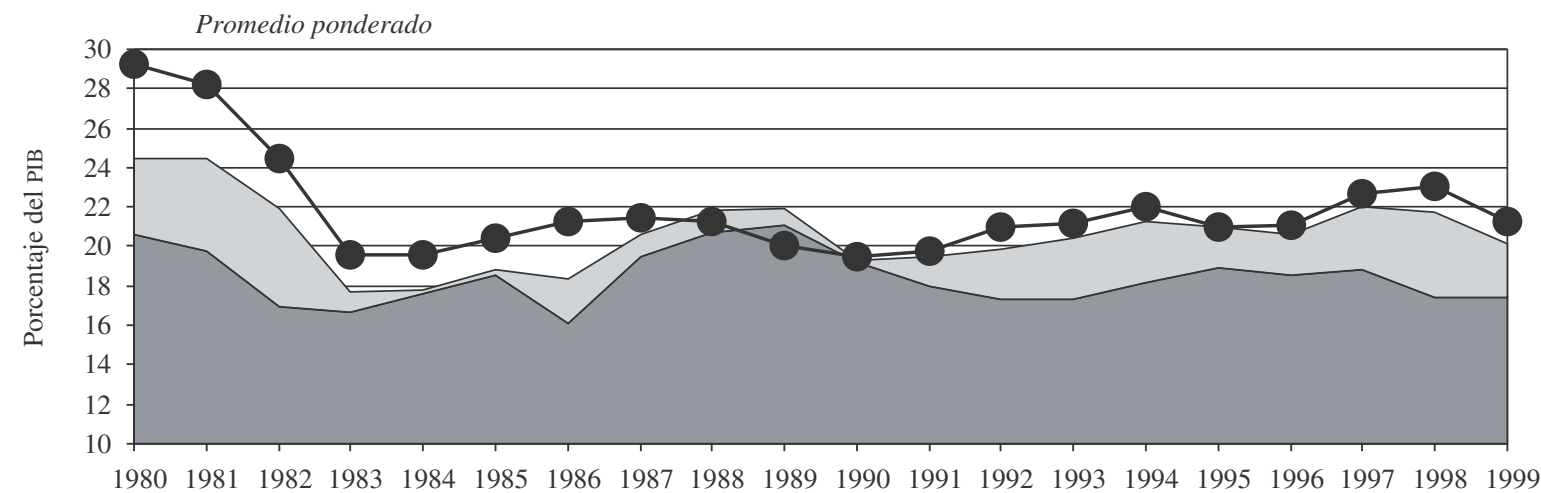

Ahorro nacional bruto

Ahorro externo

- Formación bruta de capital a precios de 1995

Fuente: Banco Mundial (2001). 
tasas de desempleo, informalidad y carencia de protección social. Las tasas de desempleo (que indican cuántos de esa población económicamente activa están sin empleo) son crecientes (gráfico 3) y, aún más, el año 2002 no se ve muy promisorio en esa materia, pues exhibe tasas del orden del 9\%

Por su parte, entre los ocupados un número cada vez mayor realiza trabajos en el sector informal. Esto

GRAFICO 3

\section{América Latina: Tasa de desempleo abierto urbano}

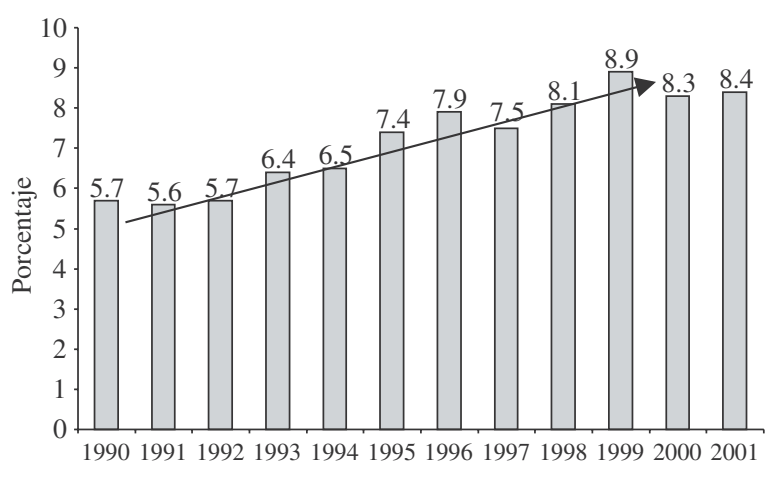

Años deriva de la tendencia a la reducción del empleo público formal y del bajo crecimiento del empleo en grandes empresas a ritmos inferiores a los de incremento de la fuerza de trabajo. En América Latina, por lo tanto, la mayoría de los ocupados se está integrando al sector informal, obviamente sin cobertura de la seguridad social.

GRAFICO 4

\section{América Latina: Estructura del empleo no agrícola}

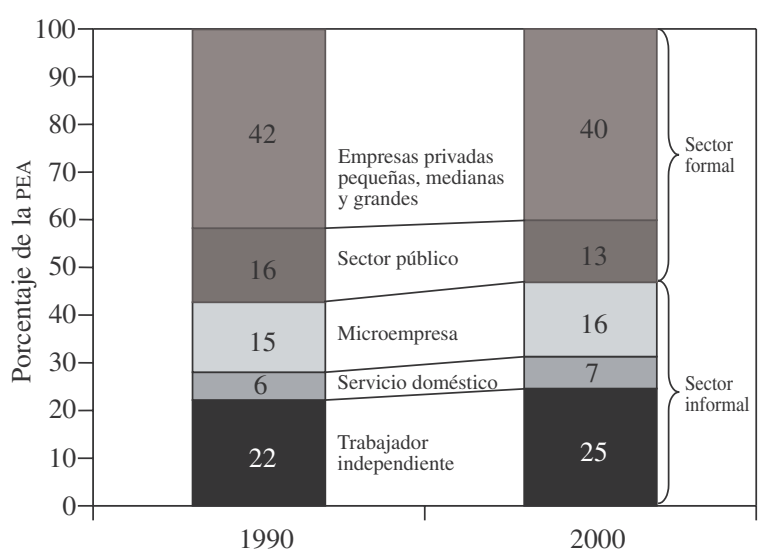

Fuente: OIT, 2001b.

Fuente: OIT, 2001b.

\section{III}

\section{Las funciones de los sistemas}

Dentro de este contexto lo que las reformas pretenden es desarrollar un sistema que cumpla dos tipos de funciones: económicas y sociales. Entre las funciones sociales la fundamental es la de asegurar el ahorro (la producción) necesario para financiar niveles de consumo satisfactorio durante la vejez, invalidez y sobrevivencia. También es importante la de contribuir a la equidad mediante la solidaridad con quienes no están en condiciones de ahorrar para la vejez. La gente que por su particular inserción laboral no tiene posibilidades de ahorro también va a llegar a la ancianidad. Los sistemas que se diseñen deben decidir qué hacer con ella. ¿Va a acceder a una pensión? Y en caso de hacerlo, ¿bajo qué condiciones y con qué financiamiento?

Pero ciertamente estas funciones no pueden impulsarse a costa de restricciones y del deterioro de objetivos económicos como la solvencia del sector público o el costo de contratación de la mano de obra. Esto sucedería si, por ejemplo, con el objeto de mejorar la cobertura del sistema se aumentaran significativamente las cotizaciones y/o la carga tributaria o el déficit fiscal. Si se construye solidaridad dentro del sistema es preciso identificar la fuente del financiamiento solidario en forma que guarde coherencia con los objetivos de competitividad y solvencia económica. Estas funciones económicas tienen importancia y actúan como condicionantes para el cumplimiento de las funciones sociales.

Entre las funciones económicas algunos incluyen también la contribución al ahorro financiero y al desarrollo de los mercados de capitales, objetivos que se han publicitado mucho con el modelo de capitalización. Sin embargo, al resaltarlas se tiende a confundir un 
medio, como es el ahorro, con un fin, como lo es la protección social. Por eso tales objetivos, deseables de por sí, deben ser secundarios al diseño del sistema, aunque no por ello dejan de ser importantes. Como veremos más adelante, tampoco está claro que la capitali- zación esté cumpliendo la función de aumentar la inversión real. Hay ahorro financiero, pero no necesariamente éste constituye inversión real. Además, en los casos en que se reemplaza un sistema de reparto hay que financiar el costo de la transición. ${ }^{1}$

\section{IV}

\section{Las opciones para diseñar un sistema de pensiones}

Para asegurar que las familias destinen un monto de sus ingresos al ahorro para la vejez, los sistemas de pensiones requieren conocer su comportamiento de consumo ante la disponibilidad actual de ingresos y las variaciones futuras de ellos. Puesto que la decisión que han de tomar dependerá de las expectativas de ingresos a lo largo de la vida del receptor principal de ingresos, se dice que es de carácter intertemporal.

La teoría del ciclo de vida asume que una persona tiene un perfil de ingreso (representado por la línea clara en el gráfico 5) que comienza cuando la persona se incorpora a la fuerza de trabajo, luego crece hasta un cierto límite y después decrece hasta desaparecer cuando se retira y no trabaja más. Sin embargo, también supone que existen las condiciones para mantener un nivel de consumo relativamente estable y ojalá creciente a lo largo de toda la vida. Por eso se necesita un sistema de pensiones que promueva el ahorro para la vejez durante el período en que la persona genera ingresos.

GRAFICO 5

Ingreso y consumo a lo largo del ciclo de vida

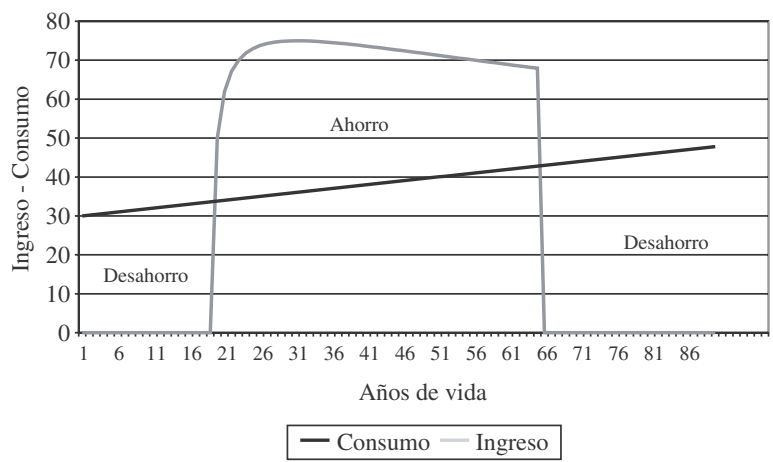

Fuente: Elaborado por el autor.
Los sistemas que se financian a partir de las contribuciones del trabajador se apoyan en esta teoría y suponen la voluntad de obtener un bien meritorio (como lo es corregir la miopía frente al ahorro para la vejez) mediante el diseño de un mecanismo para que el Estado capte, durante la vida activa del afiliado y en la forma de un impuesto o contribución a la seguridad social, una parte del ingreso actual del individuo y lo destine a financiar el sistema para asegurarle el consumo durante la vejez. Este aporte al financiamiento del sistema es más fácil de obtener de los trabajadores formales, y puede diseñarse recurriendo a distintas opciones respecto a:

i) El tipo de esquema: que puede ser de contribuciones definidas o de prestaciones definidas.

ii) El mecanismo de financiamiento: que puede ser de capitalización o de reparto, este último con distintas primas (para permitir ajustes actuariales, llegándose en casos extremos a reparto simple).

iii) La administración: que puede ser pública o privada, o una mezcla de ambas y,

iv) La participación: que puede ser obligatoria o voluntaria. $^{2}$

En los sistemas contributivos financiados por el mecanismo de reparto ha sido habitual definir los beneficios no por una relación estrecha con los montos de las contribuciones sino por la antigüedad y una regla que determina la pensión a partir de una tasa de reemplazo de los últimos o mejores salarios imponibles. En

\footnotetext{
${ }^{1}$ Véase en Orszag y Stiglitz (1999) y Barr (2000) un análisis de los mitos que existen en torno a estos temas.

${ }^{2}$ Es muy fácil decir que el trabajador independiente o informal participa voluntariamente y que si no lo hace es su problema y en consecuencia lo dejamos fuera. Con ese criterio se puede justificar la exclusión de muchos que al momento de retirarse igualmente necesitarán ingresos.
} 
los sistemas contributivos financiados por el mecanismo de capitalización ha sido habitual fijar las contribuciones y, sobre la base del monto que acumulan, definir luego los beneficios a partir de criterios actuariales basados en la esperanza de vida al momento de jubilar. Es interesante observar que este último criterio está siendo aplicado en los regímenes de reparto, a través de los modelos de capitalización nocional implementados recientemente en Brasil (Carvalho Pinheiro y Paiva Vieira, 2000).

Sin embargo, también existen sistemas de pensiones que financian los beneficios sin contribuciones directas de los beneficiarios. El Estado, a partir de impuestos generales sobre el ingreso o el consumo que aportan recursos al presupuesto fiscal, financia el pago del beneficio para el retiro de personas con derecho a él. Un caso extremo de esta modalidad es el modelo neozelandés, que define una pensión fija universal: esta pensión se ajusta de acuerdo con el índice de precios, guarda relación con el salario medio de la economía, se entrega a todo ciudadano mayor de 65 años, cualquiera haya sido su condición laboral durante su vida, y se financia enteramente con cargo a impuestos generales (St. John y Willmore, 2001).

\section{V}

\section{Esquemas de sistemas de pensiones: dos casos extremos}

Los esquemas de capitalización o de ahorro individual para la jubilación combinan algunas o todas de las siguientes características:

i) Ser contributivos: se financian a partir de aportes del trabajador.

ii) Ser de contribución definida: la prestación depende del ahorro que se acumule.

iii) Financiarse mediante la capitalización individual.

iv) Tener administración privada sólo en relación con la capitalización de los ahorros.

v) Ser obligatorios sólo para los trabajadores dependientes y no serlo para los independientes.

vi) En ellos el Estado desempeña un papel fundamental, por cuanto sigue siendo responsable del funcionamiento del sistema: cumple la función de regulador y supervisor de la gestión de las instituciones administradoras de fondos de pensiones, y además puede desempeñar un papel distribuidor para dar cobertura a quienes no alcanzan a ahorrar lo suficiente y tienen derecho a una pensión mínima o asistencial.

Por su parte, los esquemas de cobertura universal, como el de Nueva Zelandia, presentan algunas o todas de las características que se indican a continuación:

i) Ser no contributivos: se financian con impuestos generales (sobre el consumo o sobre los ingresos). ii) Entregar beneficios definidos, universales e iguales para todos: en Nueva Zelandia, cumplidos los 65 años y bajo ciertas condiciones de residencia, se otorga una pensión universal garantizada por el Estado.

iii) Ser de reparto: se pagan con los impuestos de la actual generación.

iv) Ser de administración pública.

v) Ser universal para todos los residentes: no excluye a nadie y es parejo para todos.

vi) En ellos el sector privado cumple un papel fundamental, pues se le encarga el diseño de un sistema de ahorro voluntario y complementario para los que deseen obtener beneficios mayores que los que garantiza el Estado.

Las diferentes combinaciones de las características señaladas han permitido diseñar dos esquemas totalmente opuestos, como el de Nueva Zelandia y el de Chile. El de Nueva Zelandia se preocupa de que todos tengan una pensión garantizada y el sector privado desempeña una función complementaria, la de promover mecanismos de ahorro voluntario adicional. El de Chile se preocupa del ahorro obligatorio y es el Estado el que tiene un papel subsidiario. Como se verá más adelante, en la sección VIII, existen muchas otras posibles combinaciones. Aquí sólo hemos ilustrado dos casos extremos. 


\section{VI}

\section{La heterogeneidad en el acceso a un sistema de pensiones basado en la capacidad de ahorro}

Un sistema contributivo basado exclusivamente en la capacidad individual de ahorro para la vejez tenderá a reproducir en materia de protección social las incertidumbres y restricciones que limitaron a la persona durante la etapa activa de su ciclo de vida. Estaremos reproduciendo en el sistema de protección social los mismos factores que el sistema debiera contrarrestar.

Muchas familias viven bajo restricciones de liquidez, incapaces de endeudarse contra sus ingresos futuros y de ahorrar para fines de prevención, generalmente porque sus niveles de ingresos actuales y futuros son demasiado bajos o erráticos como para sustentar niveles de ahorro continuos. O porque los agentes de los mercados de crédito perciben que esas personas tendrán dificultades para pagar préstamos, ya que no cuentan con garantías adecuadas para respaldar el crédito. Los adultos mayores de estos hogares llegan a las edades de jubilación sin ahorros para su vejez y careciendo de los ingresos necesarios para su propio sustento.

En los países donde se ha obligado a participar en sistemas de ahorro para la vejez, se observa cada vez más que la participación disminuye con el nivel de pobreza de las familias, y es aun menor entre las mujeres. Lo anterior ocurre no sólo por las bajas capacidades de ahorro de que hablábamos, sino también porque en las ocupaciones a que acceden esas personas no es posible fiscalizar con propiedad la legislación laboral, y muchas de ellas terminan sin ahorros previsionales $\mathrm{y}$, por ende, sin un ingreso para satisfacer sus niveles de consumo durante la tercera edad. En el gráfico 6 se muestran los cotizantes en el sistema privado de pensiones en Chile, agrupados según niveles de pobreza, sexo y edad. Allí se observa claramente que si el criterio para tener derecho a las prestaciones es el de las contribuciones definidas -es decir, la participación en calidad de ahorrante en el sistemaéste dejará sin prestaciones (no cubiertos) a la mayoría de las mujeres y de los miembros activos de las familias más pobres cuya participación en la actividad económica es menor y más precaria, afectando la afiliación. Aun más, dejará también no cubiertos a muchos de aquéllos que, si bien aparecen cotizando en un momento determinado, no lo hacen con regularidad y por lo tanto tendrán una baja densidad de cotización (frecuencia de ahorro). También quedarán sin cobertura aquéllos que, habiendo participado regularmente, lo hicieron con ingresos muy bajos.

Por la naturaleza de su fórmula de financiamiento, los sistemas que se diseñen a partir de la capacidad de ahorro de las familias limitarán el acceso a sus prestaciones de la siguiente forma:

i) No asegurados sin capacidad de ahorro. El caso extremo es el de las familias pobres que deben vivir exclusivamente con ingresos de subsistencia. No tienen acceso al mercado de crédito y por ende enfrentan una restricción de liquidez permanente, por lo cual ajustan su consumo al nivel de subsistencia de su ingreso actual. Su situación no cambia mayormente con el ciclo, excepto que pueden ver un número mayor de familias en situaciones similares a las de ellos. No tienen capacidad de ahorro y debieran ser sujetos de políticas asistenciales en materia de ahorro para la vejez.

ii) No asegurados altamente vulnerables. Le siguen, en una escala ascendente, aquellas familias que han podido escapar a la situación de vivir a niveles de subsistencia y pueden destinar parte de sus ingresos actuales al ahorro; sin embargo, dada su vulnerabilidad al ciclo económico y al desempleo, deberán ajustar sus gastos a niveles de subsistencia, interrumpiendo sus esfuerzos de ahorro una y otra vez y tal vez nunca puedan ahorrar con una continuidad y volumen que les garantice una pensión digna para la vejez. Estas personas también terminarán siendo objeto de pensiones asistenciales.

iii) Parcialmente asegurados por vulnerabilidad. Le siguen en la escala ascendente aquellas familias que, también siendo vulnerables a la situación del ciclo económico, deberán ajustar sus gastos a las condiciones de incertidumbre y a las restricciones de liquidez en menor forma, alcanzando una continuidad de ahorro satisfactoria, pero no un volumen que les permita una pensión digna. Por lo cual deberán ser sujetos de apoyo mediante pensiones mínimas.

iv) Plenamente asegurados por su capacidad de ahorro. Finalmente, existe un grupo de más altos 
GRAFICO 6

Chile: Cotizantes según niveles de pobreza, edad y género

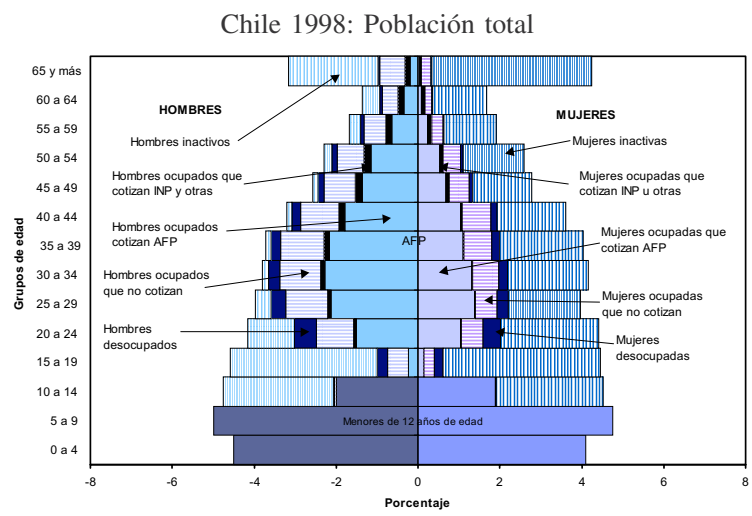

Indigentes $(5.6 \%)$

(Porcentaje de personas)

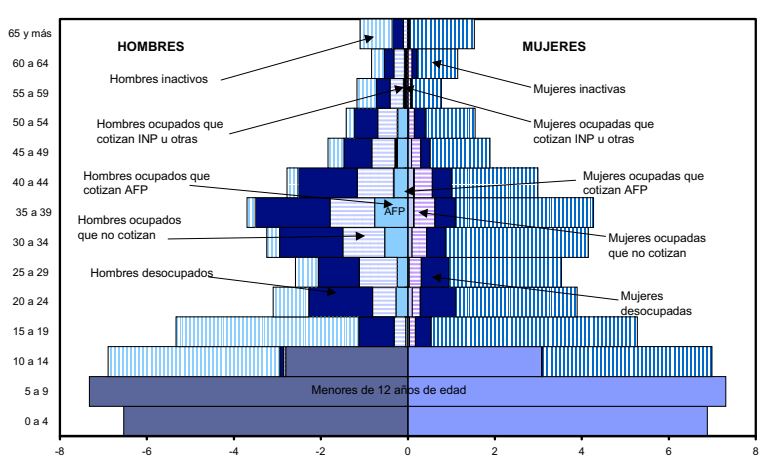

Pobres no indigentes $(16.0 \%)$

(Porcentaje de personas)

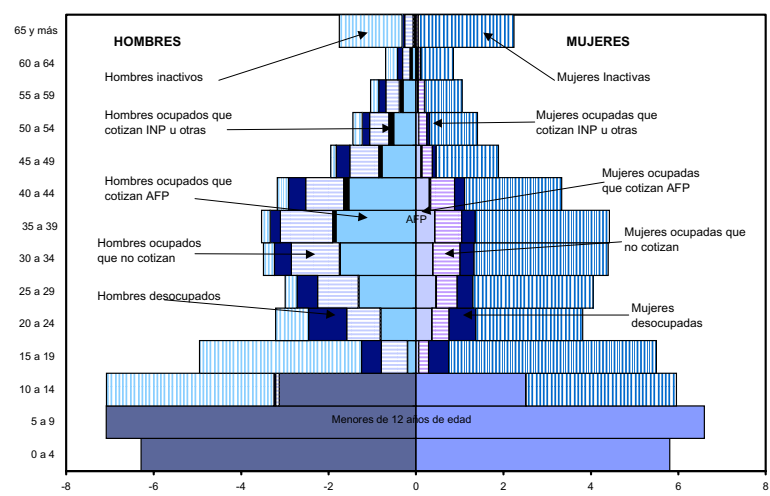

No pobres $(78.4 \%)$

(Porcentaje de personas)

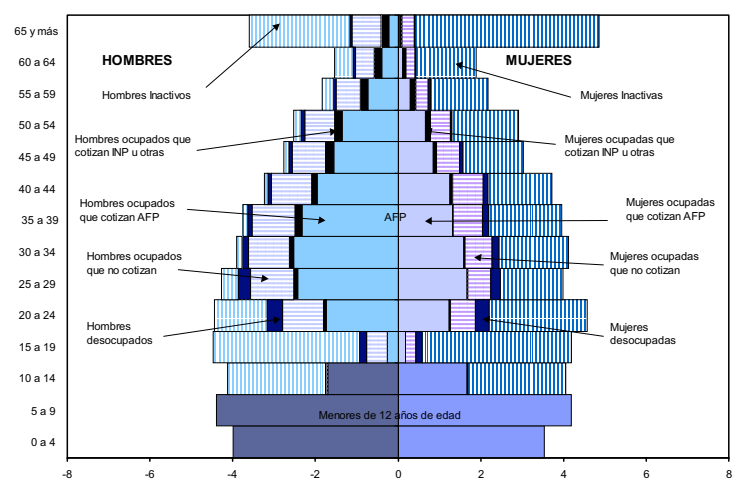

Fuente: Elaborado por el autor sobre la base de la encuesta CASEN de 1998 (MIDEPLAN, 1998).

ingresos y mayor capacitación, menos vulnerable al ciclo económico. Parte de su ingreso podrán destinarlo al ahorro en forma más continua y en mayor volumen, y así autofinanciar su consumo (pensión durante la vejez) a un nivel satisfactorio. 


\section{VII}

\section{Los pasivos contingentes y las opciones de los sistemas}

Las opciones para diseñar sistemas no son neutras y obligan a los representantes de la sociedad a pronunciarse sobre el tipo de objetivos que persiguen. El diseño tiene enormes repercusiones sobre la forma de compatibilizar las funciones sociales y económicas del sistema.

Los modelos no contributivos, de beneficios definidos, administrados por reparto, con cargo a impuesto generales, administrados por el Estado y obligatorio para todos los residentes del país pueden servir de base para un sistema universal, parejo y solidario. $\mathrm{Su}$ éxito estribará en asegurar un ingreso adecuado a todos los ciudadanos que llegan a la edad de jubilación, no sólo a aquéllos que contribuyeron a la actividad económica, moderando la desigualdad de ingreso entre los jubilados y protegiéndolos contra la incertidumbre de rápidos cambios sociales y económicos. Si bien privilegia la función social al asegurar el acceso universal a sus prestaciones, sólo es aceptable, y fiscalmente responsable, si los beneficios pueden financiarse en forma sustentable a lo largo del tiempo.

El modelo aplicado en Nueva Zelandia privilegia la equidad y universalidad, garantizando el acceso a ingresos para la época de jubilación sólo por el hecho de haber sido ciudadano por más de 10 años y haber contribuido en cualquier forma a la sociedad, sin hacer distinciones. Su financiamiento, en cambio, genera una pesada carga fiscal y no contribuye al desarrollo del mercado de capitales. Cuando el financiamiento proviene de impuestos al consumo puede ser regresivo, pero el hecho de destinarse a pensiones parejas que son imponibles permite a la postre recuperar a través de los impuestos parte de los costos de quienes perciben rentas mayores. Al no ser contributivo, tiene la ventaja de minimizar las distorsiones que impiden la contratación de mano de obra. Sus pensiones se reajustan conforme a la inflación pero no pueden estar por debajo del $65 \%$ del salario medio. El costo de este beneficio ha llegado a representar alrededor de $5 \%$ del PIB en 2000 y se espera sea algo inferior a $11 \%$ en 2050 (St. John y Willmore, 2001).

Cálculos preliminares e ilustrativos de esta opción para países de América Latina se presentan en el cuadro 1. Ellos muestran que el modelo es sensible no sólo a la proporción de personas que superan los 65 años, sino que en particular al monto del beneficio, en este

CUADRO 1

América Latina: El desafío de financiar una pensión universal (Para datos de 2001)

\begin{tabular}{lcccc}
\hline País & $\begin{array}{c}\text { Monto de } \\
\text { la pensión } \\
\text { (dólares) }\end{array}$ & $\begin{array}{c}\text { Mayores de } \\
65 \text { años } \\
(\%)\end{array}$ & $\begin{array}{c}\text { Pensión/PIB } \\
\text { per cápita } \\
(\%)\end{array}$ & $\begin{array}{c}\text { Costo como } \\
\text { porcentaje del PIB } \\
(\%)\end{array}$ \\
\hline Argentina & 200.1 & 9.7 & 2.8 & 3.3 \\
Bolivia & 60.5 & 4.1 & 6.5 & 3.2 \\
Brasil & 73.3 & 5.3 & 2.4 & 1.6 \\
Chile & 162.5 & 7.3 & 3.8 & 3.3 \\
Colombia & 124.4 & 4.8 & 6.4 & 3.7 \\
Ecuador & 121.0 & 4.8 & 8.7 & 5.0 \\
México & 106.6 & 4.8 & 1.7 & 1.0 \\
Paraguay & 182.2 & 3.5 & 13.9 & 5.9 \\
Perú & 116.9 & 4.8 & 5.8 & 3.3 \\
Uruguay & 82.0 & 12.9 & 1.5 & 2.3 \\
Venezuela & 212.3 & 4.5 & 4.2 & 2.3 \\
\hline
\end{tabular}

Fuente: Elaborado por el autor sobre la base de información oficial de la CEPAL. 
caso estimado igual al salario mínimo y cuya "generosidad" se aprecia a través de su relación con el PIB per cápita. Los países aumentan el costo económico de sustentar esta opción (medido como porcentaje del PIB) no sólo como consecuencia de la mayor proporción de población superior a 65 años, sino que en especial por el grado de generosidad relativa del beneficio, medido por la relación entre el salario mínimo y el PIB per cápita, como se aprecia en el caso extremo de Paraguay, cuyo envejecimiento es incipiente pero exhibe un salario mínimo elevado (cuadro 1 y gráfico 7).

En el otro extremo se halla un sistema que premia el esfuerzo individual de financiar una pensión a partir del ahorro realizado durante la vida activa. Este no privilegia la función social, ya que no garantiza cobertura universal y el beneficio difiere entre individuos, pudiendo quedar muchos sin asegurar. Se basa en contribuciones definidas y en la capitalización individual. Para contribuir al desarrollo del mercado de capitales, es preciso que haya una primera fase (hasta que toda una generación se integre al sistema) de altos costos de transición que comprometen responsabilidades fiscales importantes. La pensión que otorga este sistema se basa en el ahorro. Si éste es muy bajo -inferior a las garantías establecidas - puede llegar a desplazar a muchos hacia los beneficios subsidiados por el Estado, comprometiendo la solvencia de las cuentas fiscales.

El modelo chileno se asemeja a esta alternativa, ya que discrimina entre quienes tienen y no tienen capacidad de ahorro, y entre los primeros selecciona a aquéllos a quienes el Estado puede obligar a cotizar y puede fiscalizar. Su creación a partir de un antiguo

\section{GRAFICO 7}
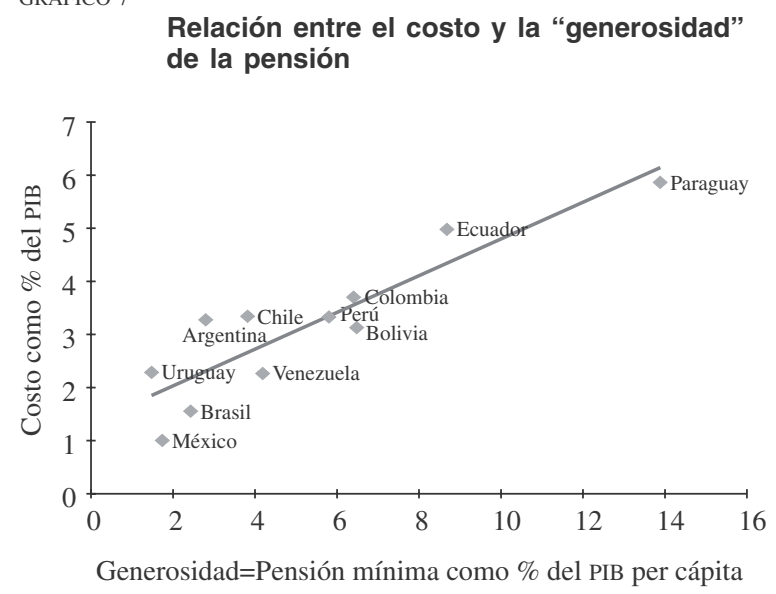

Fuente: Cuadro 1 sistema de reparto generó una importante carga fiscal para cubrir los costos de transición que implican el pago de las pensiones en curso y los reconocimientos por contribuciones al sistema antiguo de quienes se trasladan al nuevo. Además, origina un costo por las garantías a las pensiones mínimas y asistenciales de la población civil y por las pensiones de las Fuerzas Armadas.

El costo anual de la transición, las garantías y las pensiones de las Fuerzas Armadas se ha estimado en 5.5\% del PIB durante los primeros 21 años (gráfico 8). En el largo plazo, el costo deberá converger al monto equivalente a las garantías. Este dependerá del número de personas que queden subaseguradas o no aseguradas debido a sus bajos montos de ahorro y el aumento de sus esperanzas de vida, y de las pensiones de las Fuerzas Armadas, mientras éstas sigan en el régimen actual. Por su parte, las pensiones de los afiliados que quedan asegurados son inciertas, pues dependen de la densidad de sus cotizaciones, de la rentabilidad que obtengan durante su período de contribución y de su esperanza de vida al jubilarse. Además, es preciso descontar las comisiones cobradas por las administradoras de fondos de pensiones durante el período de acumulación, y la prima de seguro para adquirir una renta vitalicia (hay otras opciones) para el período de jubilación. Los beneficios garantizados bajo la forma de pensiones asistenciales y pensiones mínimas son en la actualidad muy inferiores al salario mínimo (gráfico 8).

El impacto sobre el desarrollo del mercado de capitales se potencia en la medida que el Estado haya financiado este costo a través de mayores impuestos, menores gastos en otros sectores y recursos provenien-

GRAFICO 8

Chile: Déficit previsional total

(Porcentaje del PIB)

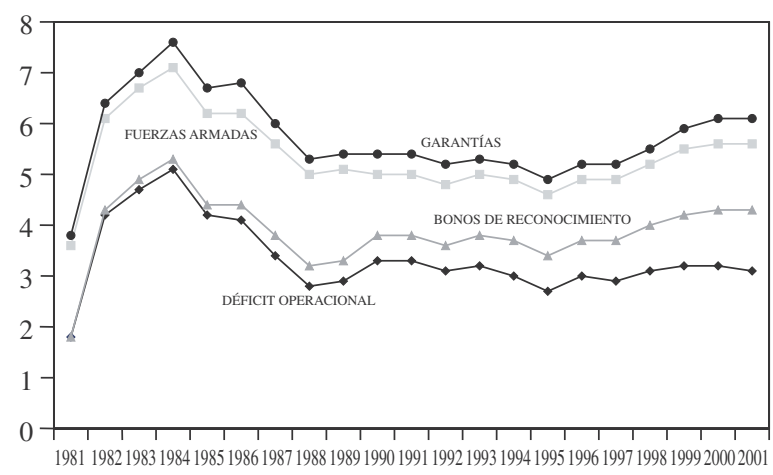

Fuente: Arenas de Mesa (1999). 
tes de las privatizaciones. De lo contrario, el Estado se transforma en el principal demandante de los recur- sos del fondo de pensiones, minimizando su impacto sobre el desarrollo del mercado de capitales.

\section{VIII}

\section{Situación actual de los esquemas de capitalización en América Latina}

En las reformas estructurales a los modelos contributivos, los esquemas de capitalización no siempre han sustituido a los antiguos de reparto. Hay cuatro tipos de modelos: los de sustitución de un esquema de reparto por uno de capitalización individual (Chile en 1981, Bolivia en 1997, México en 1997 y El Salvador en 1998); los mixtos, de complementación de un sistema de reparto con uno de capitalización (Argentina en 1994, Uruguay en 1996 y Costa Rica en 2001); los paralelos, de competencia entre un modelo de reparto y uno de capitalización (Colombia en 1994 y Perú en 1993), y el modelo nocional que aplica los esquemas de contribuciones definidas a los mecanismos de reparto (Brasil en 2000). ${ }^{3}$

Existen tres temas fundamentales en que se manifiestan las limitaciones que el mercado de trabajo impone a los sistemas que incorporan cuentas de capitalización individual: la cobertura, el desarrollo del mercado de capitales y los costos de las comisiones. ${ }^{4}$

\section{Cobertura}

Según se observa en el gráfico 9, los esquemas de capitalización continúan excluyendo a un alto porcentaje de la población económicamente activa y, por ende, dejan a cargo de otras fuentes la ampliación de la cobertura. En términos de personas afiliadas, un informe de la Asociación Internacional de Organismos de Supervisión de Fondos de Pensiones (AIOs) para el promedio simple de nueve países muestra una alta cobertura: $63.7 \%$ de la población económicamente activa a diciembre de 2001. Sin embargo, aquéllos que efectivamente aportan al sistema tan sólo son un $27.7 \%$

\footnotetext{
3 Véase Mesa-Lago (1999) y Carvalho Pinheiro y Paiva Vieira (2000).

${ }^{4}$ Las diferentes características de los países, así como de cada sistema en particular, junto a la diversa antigüedad de éstos, aconsejan cautela al hacer cualquier comparación.
}

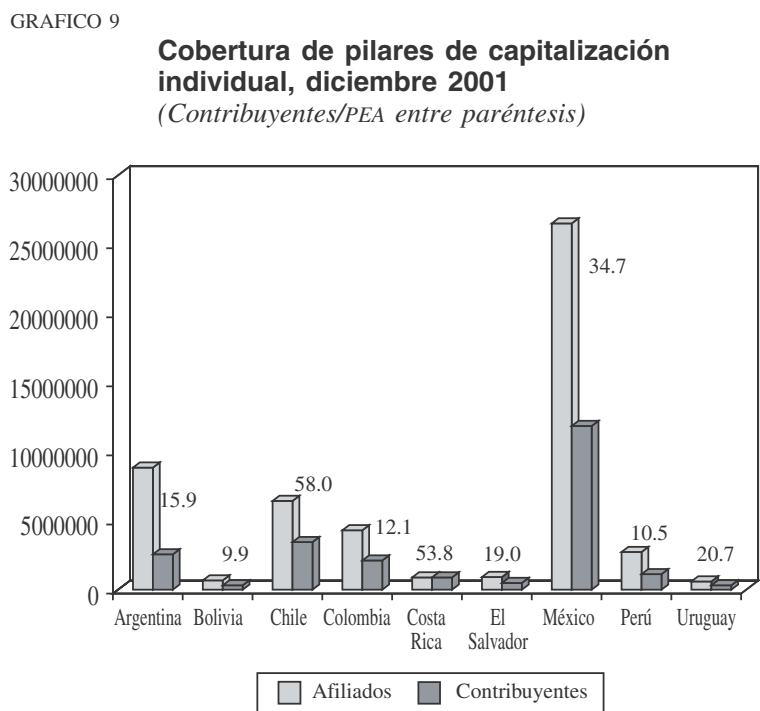

Fuente: AIOS, 2001.

de la misma; es decir, aproximadamente seis de cada diez afiliados no aportan regularmente al sistema. Esta diferencia entre afiliados y aportantes permite especular que la densidad con que los afiliados ahorran en el sistema es muy baja, lo que les impedirá acumular lo suficiente para financiar su propia pensión, por lo que deberán recibir subsidios del Estado en calidad de subasegurados o no asegurados beneficiarios de pensiones básicas (mínimas) y asistenciales.

Cifras del Ministerio del Trabajo de Chile indican que sólo cotiza el $4 \%$ de los trabajadores independientes (si bien no están obligados a cotizar), y que más de la mitad de las mujeres afiliadas cotiza menos del $30 \%$ del tiempo que trabaja, proporción que sube a $40 \%$ en el caso de los hombres. Otro estudio para Chile indica que la mayoría de los afiliados se limita a cotizar lo justo para recibir la pensión mínima garantizada por el Estado — que hoy es de algo más de 100 dólares- y luego invierten sus recursos en otras cosas, 
como educación de los hijos y casa propia (El Mercurio, 2002).

\section{Desarrollo del mercado de capitales y rentabi- lidad}

La posibilidad de que el esquema de capitalización contribuya efectivamente a la generación de empleo mediante el desarrollo del mercado de capitales y a hacer más rentables los fondos de pensiones, depende de múltiples factores. En primer lugar, debe existir un contexto apropiado para decisiones de inversión de largo plazo, caracterizado por una inflación baja y controlada (y/o un sistema financiero indizado), tasas positivas pero moderadas de interés real; y un tipo de cambio realista. El propósito es crear horizontes de planeación de largo plazo, que permitan asignar eficientemente los recursos de capital, en condiciones de competitividad internacional.

También se necesitan medidas institucionales en el ámbito financiero que generen una sana competencia por los recursos de inversión de largo plazo. Esto incluye mejorar la solvencia del sector público; llevar adelante la regulación prudencial y organizacional de la banca con miras a evitar las crisis, y desarrollar el mercado de valores de modo de facilitar una transparencia en el análisis de riesgos que permita tomar decisiones informadas de inversión, y proteger a los inversionistas minoritarios.

Tanto la falta de tales medidas como la imposición de estrictas regulaciones a los fondos de pensiones han impedido hasta el momento que haya una amplia diversificación de su cartera de inversiones, que se concentra en gran medida en títulos de la deuda gubernamental. Del total de fondos administrados por estos sistemas, el 59\% está invertido en títulos de la deuda gubernamental, el $18 \%$ en títulos de instituciones financieras y sólo un $8 \%$ en acciones (gráfico 10).

El impacto directo de los fondos sobre la inversión real es incierto. Con excepción de la inversión en letras hipotecarias cuya contrapartida es la construcción de viviendas para ser adquiridas por el público que se endeuda, no existen otros instrumentos cuya contrapartida sea el aumento de riqueza en el país, en lugar de la compra de activos ya existentes o el financiamiento de gastos corrientes.

La rentabilidad anual bruta ${ }^{5}$ de los fondos desde su vigencia ha sido elevada en todas las experiencias,

\footnotetext{
${ }^{5}$ Sin considerar el efecto de las comisiones que cobran las administradoras.
}

guardando relación con la valorización que han experimentado los títulos de la deuda gubernamental, pero en los últimos años ha experimentado fuertes reducciones. Mientras el promedio simple de las rentabilidades históricas reales ${ }^{6}$ ha sido de $10.4 \%$, el de enero a diciembre de 2001 fue tan sólo de 5.9\% (gráfico 11). Por cierto, la rentabilidad de cada individuo dependerá del año en que entró y salió del esquema de capitalización, y de la rentabilidad del fondo en ese período, descontadas las comisiones.

\section{GRAFICO 10 \\ América Latina (ocho países): Composición de los Fondos Administrados}

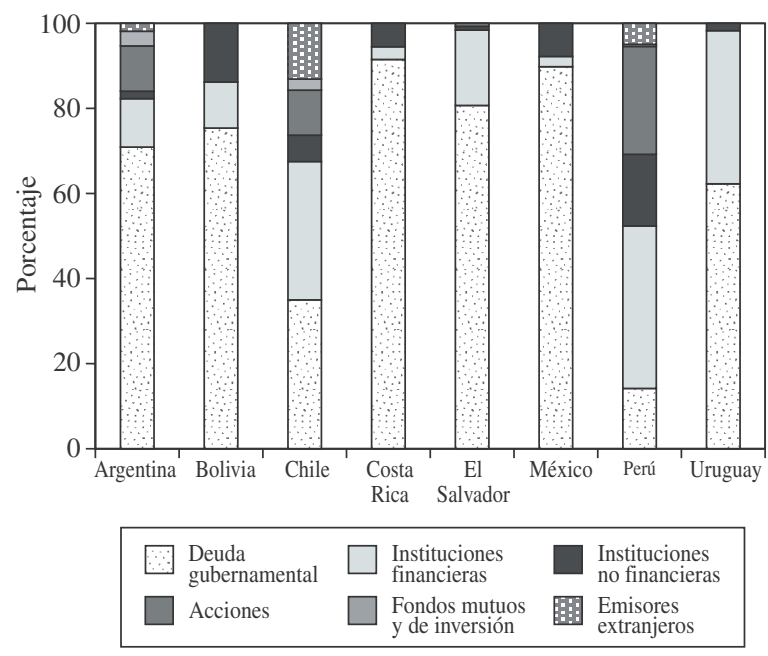

Fuente: AIOS, 2001.

GRAFICO 11

América Latina (ocho países): Rentabilidad bruta real de los fondos de pensiones

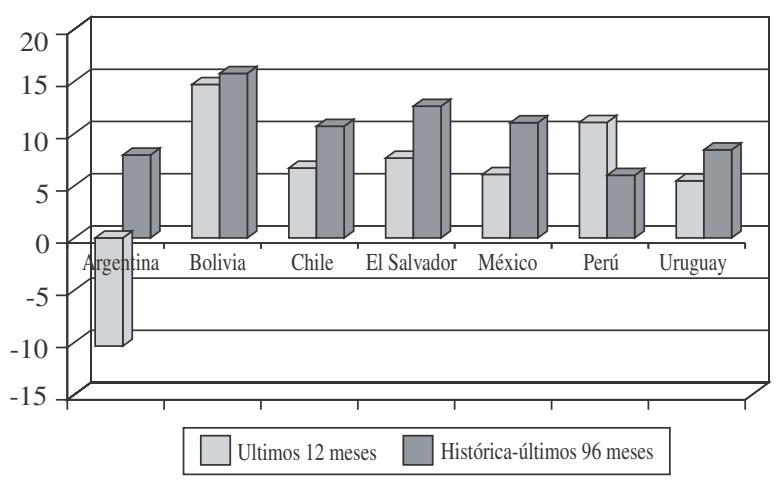

Fuente: AIOS, 2001.

\footnotetext{
${ }^{6}$ Es decir, deflactando la rentabilidad nominal por la variación de precios al consumidor.
} 


\section{Costos de las comisiones}

No deja de llamar la atención que, frente a estas circunstancias, quienes contribuyen al esquema de capitalización deban pagar una serie de recargos sobre su aporte a la cuenta individual, los cuales se descomponen en un seguro de invalidez y seguro de vida y una comisión neta para los gastos de la administradora del fondo respectivo. Según el informe de la AIOs, en promedio para la región y como porcentaje de su salario imponible, la comisión total que paga un trabajador latinoamericano es de $3 \%$, la que se descompone en $1.25 \%$ para un seguro de invalidez y seguro de vida y en $1.75 \%$ para la comisión de la administradora. Las administradoras deben capitalizar en promedio un $9 \%$ del salario imponible. En definitiva, el promedio simple entre países del costo de las comisiones sobre el aporte total de los trabajadores es de $25 \%$, y aquél estimado sobre el aporte capitalizable es de $33 \%$, existiendo importantes diferencias entre países. ${ }^{7}$

Teniendo en cuenta las características de la cobertura, y las proyecciones que indican que muchos de los trabajadores no alcanzarán a ahorrar lo suficiente como para beneficiarse del esquema de capitalización, cabe preguntarse si acaso el pago de comisiones a las ad- ministradoras de fondos de pensiones es una contribución que el sistema pierde como parte del financiamiento y administración de los beneficios que garantiza el Estado. ${ }^{8}$

El tema de las comisiones ha sido ampliamente debatido, incluso en relación con los trabajadores que quedan plenamente asegurados por el esquema de capitalización. En esos casos se argumenta que la rentabilidad de la cuota difiere de aquélla de la cuenta del trabajador porque no considera el costo de las comisiones. Este costo lo asume el trabajador. Esto se ilustra para el caso chileno en el cuadro 2. Si bien la rentabilidad de la cuota (forma en que se valora la participación en el monto total del fondo administrado por una AFP) entre 1981 y 1999 fue de $11.2 \%$, la de la cuenta de los diferentes individuos difirió significativamente, según el nivel de ingreso y período de cotización de cada cual. Se concluye que el afiliado asume en forma regresiva el costo de las comisiones y el riesgo financiero del sistema. Si un afiliado ha debido participar en el sistema cuando las comisiones eran altas y la rentabilidad baja, tendrá de por sí una pensión significativamente inferior a otro que ha participado en períodos de rentabilidad alta y comisiones bajas. Esta situación es mucho peor para los afiliados de bajos ingresos.

CUADRO 2

Chile: Rentabilidad anual de la cuenta individual y de la cuota

(Porcentajes)

\begin{tabular}{|c|c|c|c|c|c|c|}
\hline Pesos chilenos & 80500 & 147954 & 221930 & 443861 & 887722 & Cuota \\
\hline Mayo de 1998 a abril de 1999 & 3.79 & 3.91 & 3.95 & 4.00 & 4.02 & 4.81 \\
\hline Mayo de 1996 a abril de 1999 & 3.21 & 3.28 & 3.31 & 3.34 & 3.35 & 4.62 \\
\hline Mayo de 1993 a abril de 1999 & 5.04 & 5.10 & 5.13 & 5.15 & 5.16 & 7.05 \\
\hline Mayo de 1987 a abril de 1999 & 6.97 & 7.09 & 7.14 & 7.19 & 7.22 & 9.09 \\
\hline Mayo de 1981 a abril de 1999 & 7.24 & 7.41 & 7.47 & 7.54 & 7.57 & 11.17 \\
\hline
\end{tabular}

Fuente: Superintendencia de Administradoras de Fondos de Pensiones (1999).

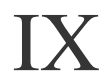

\section{Conclusiones}

El diseño de un sistema de pensiones debe tener como función social fundamental la de alcanzar la cobertura universal: proveer de ingresos dignos tanto en casos de vejez e invalidez de quienes son percepto-

\footnotetext{
${ }^{7}$ Debido a los diferentes conceptos y experiencias estas comparaciones deben examinarse con cautela.
}

res de ingresos, y sobrevivencia de dependientes tras su fallecimiento, como en casos de quienes no lo son.

\footnotetext{
${ }^{8}$ Este argumento pierde fuerza cuando el aporte contributivo y su capitalización se utilizan para financiar parte de las garantías del trabajador que queda subasegurado y la comisión se considera un pago por los servicios de capitalización del saldo del trabajador en ese lapso.
} 
En lo fundamental, el conflicto con las funciones económicas se manifiesta en las responsabilidades fiscales que puede tener que asumir el Estado como consecuencia del desafío que el diseño del sistema le asigna: el de dar cobertura a diferentes personas, cualquiera haya sido su inserción laboral.

Un esquema contributivo de reparto, de prima media escalonada y beneficios definidos, corre el riesgo de transformarse en un sistema simple de reparto por erosión del fondo de reserva, lo que puede llegar a exigir un alto componente de financiamiento público. Sin embargo, su sustitución por un sistema financiado mediante cuentas de ahorro individuales no escapa del todo a esta tendencia, debido a que el mercado de trabajo limita la capacidad de muchos de sus afiliados para alcanzar la densidad necesaria de contribuciones $\mathrm{y}$, por ende, los hará igualmente acreedores a las garantías estatales, cuyos costos deberán sumarse a los de la transición.

De ahí que las responsabilidades fiscales no desaparezcan y que el Estado deba asumir diversos compromisos. Estos incluyen:

- El pago de las pensiones actualmente en curso de los jubilados en el sistema antiguo.

- El pago de los derechos ya adquiridos por los actuales contribuyentes a través de sus contribuciones al sistema antiguo, cuando éstos se trasladan al nuevo.

- El pago de las pensiones garantizadas por el Estado, ya sean pensiones mínimas, asistenciales, de las Fuerzas Armadas o de otros grupos que tienen derecho a ellas por ley.

Para su financiamiento dispone del fondo neto de reserva del sistema antiguo.

Es difícil estimar el costo de estas responsabilidades. En parte porque no todos los países han optado por una sustitución total de un sistema por otro, debido precisamente a los muy elevados compromisos fiscales que esto entrañaría. Pero en general los países han debido enfrentarse a este dilema al diseñar sus sistemas de pensiones, y en caso de realizar la reforma sustituyendo un sistema por otro han debido optar por las siguientes alternativas:

- No asumir las responsabilidades señaladas, lo cual tiene un alto costo político y perjudica a pensionados y trabajadores que cotizaron en el sistema antiguo.

- Financiarlas con nueva deuda, lo cual tiene un costo para las generaciones futuras y afecta la demanda de recursos financieros del sector público.

- Financiarlas con superávit fiscal, lo que tiene fuertes implicaciones fiscales y afecta a las actuales generaciones.

Frente a estos dilemas, Argentina, Uruguay, Colombia, Perú y Costa Rica optaron por sistemas con dos pilares - de reparto y de capitalización- y ajustaron el esquema de reparto para hacerlo más viable desde el punto de vista financiero, ya sea aumentando la edad de jubilación, aumentando la cotización y/o reduciendo las pensiones. En todo caso, no se ha previsto debidamente que una vez que un esquema de capitalización alcanza su madurez:

- Muchas personas calificarán igualmente para recibir pensiones mínimas y/o asistenciales, lo que obligará a efectuar mayores ajustes en las finanzas públicas o reformas a las reformas.

- Los que están alcanzando la edad de jubilación con ahorros suficientes deberán ajustar sus beneficios a los crecientes aumentos de la esperanza de vida, viéndose igualmente abocados a decisiones de aumentar su edad de jubilación, reducir sus beneficios o hacer contribuciones voluntarias adicionales.

Frente a la heterogeneidad de las sociedades latinoamericanas, que se manifiesta principalmente a través del mercado de trabajo, cabe concluir que es necesario continuar reformando los sistemas de pensiones. Hay que fortalecer sus mecanismos de financiamiento contributivo y solidario para que permitan dar cobertura a quienes, por su particular inserción laboral, quedarán en calidad de no asegurados o subasegurados en los esquemas de capitalización individual. 
Bibliografía

AIOS (Asociación Internacional de Organismos de Supervisión de Fondos de Pensiones) (2001): Boletín estadístico, $\mathrm{N}^{\circ} 6$, Buenos Aires, diciembre.

Arenas de Mesa, A. (1999): Efectos fiscales del sistema de pensiones en Chile: Proyección del déficit previsional: 1999-2037, trabajo presentado al seminario "Responsabilidades fiscales de los sistemas de pensiones", Santiago de Chile, Ministerio de Hacienda/ Comisión Económica para América Latina y el Caribe (CEPAL), Santiago de Chile, 2 y 3 de septiembre.

(2000): El sistema de pensiones en Chile: principales resultados y desafios pendientes, serie Seminarios y conferencias, $\mathrm{N}^{\circ}$ 2, LC/L.1399-P, Santiago de Chile, CEPAL.

Banco Mundial (2001): World Development Indicators 2001, Washington, D.C.

Barr, N. (2000): Reforming Pensions: Myths, Truths, and Policy Choices, IMF working paper, $\mathrm{N}^{\circ} 139$, Washington, D.C., Fondo Monetario Internacional.

Carvalho Pinheiro, V. y S. Paiva Vieira (2000): Reforma previsional en Brasil: la nueva regla para el cálculo de los beneficios, serie Financiamiento del desarrollo, $N^{\circ}$ 97, LC/L.1386-P, Santiago de Chile, CEPAL.

CEPAL (Comisión Económica para América Latina y el Caribe) (1996): Fortalecer el desarrollo. Interacciones entre macro y microeconomía, LC/G.1898, Santiago de Chile.

CEPAL/CELADE (Comisión Económica para América Latina y el Caribe/Centro Latinoamericano y Caribeño de Demografía) (1999): América Latina: población económicamente activa, 1980-2025, Boletín demográfico, año 32, N 64, LC/G.2059, Santiago de Chile.

(Comisión Económica para América Latina y el Caribe/ Centro Latinoamericano y Caribeño de Demografía) (2002): América Latina y el Caribe: estimaciones y proyecciones de población, 1950-2050, Boletín demográfico, año 35, $\mathrm{N}^{\circ} 69$, LC/G.2152-P, Santiago de Chile.
El Mercurio (2002): Santiago de Chile, 8 de agosto de 2002, página B.6.

Mesa-Lago, C. (1999): La reforma estructural de pensiones en América Latina: Tipología, comprobación de presupuestos y enseñanzas, en A. Bonilla y A. Conte-Grand (comps.), Pensiones en América Latina. Dos décadas de reforma, Lima, Organización Internacional del Trabajo (OIT).

MIDEPLAN (Ministerio de Planificación y Cooperación) (1998) Encuesta de caracterización socioeconómica nacional, CASEN 1998, Santiago de Chile.

Ocampo, J.A. (coord.) (2001): Crecer con estabilidad. El financiamiento del desarrollo en el nuevo contexto internacional, Santafé de Bogotá, CEPAL/Alfaomega.

OIT (Organización Internacional del Trabajo) (2001a): Seguridad social: temas, retos y perspectivas, Ginebra.

(2001b): Panorama Laboral 2001. América Latina y el Caribe, Lima.

Orszag, P. y J. Stiglitz (1999): Rethinking pension reform: ten myths about social security systems, trabajo presentado en la Conferencia del Banco Mundial "New Ideas About Old-Age Security", Washington, D.C., Banco Mundial, 14-15 de septiembre.

St. John, S. and L.Willmore (2001): Two legs are better than three: New Zealand as a model for old age pensions, World Development, vol. 29, № 8, Oxford, Reino Unido, Pergamon Press, Ltd.

Superintendencia de Administradoras de Fondos de Pensiones (1999): Boletín estadístico, $\mathrm{N}^{\circ} 149$, Santiago de Chile.

Titelman, D. y A. Uthoff (1997): La relación entre el ahorro externo y el ahorro nacional en contextos de liberalización financiera, en R. Ffrench-Davis y H. Reisen (comps.), Flujos de capital e inversión productiva: lecciones para América Latina, Santiago de Chile, Mc Graw-Hill. 